\title{
The Graz seismo-electromagnetic VLF facility
}

\author{
K. Schwingenschuh ${ }^{1}$, G. Prattes ${ }^{1}$, B. P. Besser ${ }^{1}$, K. Močnik ${ }^{1}$, M. Stachel ${ }^{1}$, Ö. Aydogar ${ }^{1}$, I. Jernej ${ }^{1}$, M. Y. Boudjada ${ }^{1}$, \\ G. Stangl ${ }^{1}$, A. Rozhnoi ${ }^{2}$, M. Solovieva ${ }^{2}$, P. F. Biagi ${ }^{3}$, M. Hayakawa ${ }^{4}$, and H. U. Eichelberger ${ }^{1}$ \\ ${ }^{1}$ Space Research Institute, Austrian Academy of Sciences, Graz, Austria \\ ${ }^{2}$ Institute of the Earth Physics, Russian Academy of Sciences, Moscow, Russia \\ ${ }^{3}$ Department of Physics, University of Bari, Bari, Italy \\ ${ }^{4}$ The University of Electro-Communications (UEC), Advanced Wireless Communications Research Center and Research \\ Station on Seismo Electromagnetics, Chofu Tokyo, Japan
}

Received: 15 November 2010 - Revised: 18 February 2011 - Accepted: 16 March 2011 - Published: 20 April 2011

\begin{abstract}
In this paper we describe the Graz seismoelectromagnetic very low frequency (VLF) facility, as part of the European VLF receiver network, together with the scientific objectives and results from two years operation. After a brief technical summary of the present system - with heritage from a predecessor facility - i.e. hardware, software, operational modes and environmental influences, we discuss results from statistical data and scientific events related to terrestrial VLF propagation over Europe.
\end{abstract}

\section{Introduction}

The VLF facility is part of a network which aims at solving some fundamental problems related to the development of earthquake (EQ) forecast methods, summarised as seismoelectromagnetic investigations. Seismic activity could modify the Earth surface - ionosphere cavity properties and causes variations in the wave propagation pattern between VLF transmitters and receivers. In the first section we discuss the scientific background and objectives, followed by a description of the VLF network with emphasis on the Graz receiving system. We finally focus on scientific results in terms of statistics and event based studies.

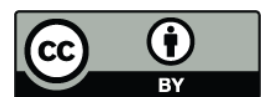

Correspondence to: K. Schwingenschuh (konrad.schwingenschuh@oeaw.ac.at)

\section{Scientific objectives}

The main scientific goal is to pinpoint and distinguish local and mesoscale VLF perturbations - within an influence zone, which has to be determined (Fresnel zone in ray propagation) - connected with e.g. earthquakes, volcano eruptions and man-made artefacts from large-scale or global anomalies related to atmospheric circulation, magnetic storms, substorms, solar flares or energetic particle precipitation into the atmosphere. Secondary goals in a broader sense within this multi scale view are to find a modus vivendi between characterisation of general phenomena which alter the propagation cavity (waveguide picture). For the strong L'Aquila EQ the scientific objectives could be achieved (references below) and natural large scale perturbations are regularly observed. The properties of the VLF waveguide are network-wide investigated, finally the signal-to-noise ratio of the facility sets the lower limit and conclusiveness about tiny variations is under debate.

\section{The European VLF network}

A geographical overview of the currently operational European VLF transmitter/receiver stations in seismoelectromagnetics is shown in Fig. 1. Their distribution enables the remote determination of local VLF field perturbations of various origins, among them contributions from strong EQs and active volcanos. Such a widespread radio reception allows the investigation of the VLF/LF electromagnetic situations along the different propagation paths due to path combinations of different stations at crossing areas (nodes). VLF/LF ground based activities (Schwingenschuh et al., 2010a) are complemented by investigations at

Published by Copernicus Publications on behalf of the European Geosciences Union. 


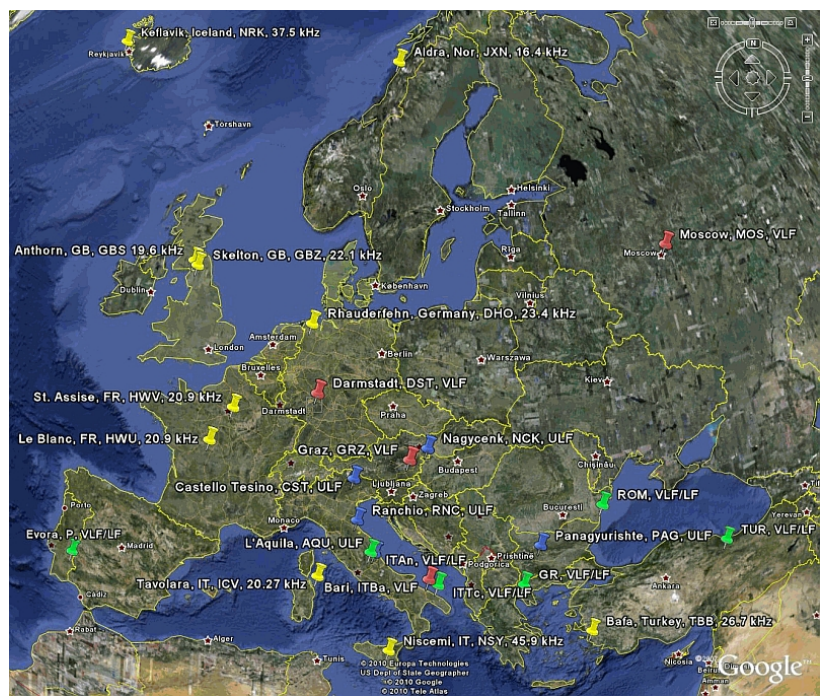

Fig. 1. Station network for combined investigations of local and mesoscale geophysical/seismic phenomena, consisting of (i) VLF only (red markers), (ii) VLF/LF (green), (iii) South European Geomagnetic Array (SEGMA) ULF (blue) receiving stations, and (iv) European VLF transmitters (yellow), LF transmitters not shown - Google Earth map.

ultra low frequency (ULF) (Prattes et al., 2008; Prattes et al., 2010b), VLF DEMETER satellite (e.g. Němec et al., 2009) and GPS total electron content (TEC) measurements (e.g. Pulinets and Boyarchuk, 2004). The network has scientific heritage mainly from Russian and Japanese EQ investigations in Asian seismic areas over the last decades. Pioneering work was carried out by several research groups (e.g. Molchanov and Hayakawa, 2008; Hayakawa, 2007, 2009; Hayakawa and Hobara, 2010). The capability of the combined investigations of a VLF network (Rozhnoi et al., 2009) (Schwingenschuh et al., 2010b) together with ULF (Schwingenschuh et al., 2009) (Prattes et al., 2010a) and DEMETER satellite data (Boudjada et al., 2010) has been demonstrated for the L'Aquila earthquake, 6 April 2009. During that springtime with EQ swarms in the Abruzzo area, an OmniPal system worked at Graz VLF receiving side and paths from the two Italien transmitters crossed the seismic active region.

\subsection{Receivers}

In order to investigate EQ forecasting methods based on observation of VLF electromagnetic signals, data from a dedicated observation network with stations distributed over Europe are essential (Table 1). These stations are equipped with VLF and partly LF (Biagi et al., 2009, 2010) receivers in the frequency range from $10-50 \mathrm{kHz}$ (for $\mathrm{LF}$ up to $270 \mathrm{kHz}$ ), which analyse the signals from powerful VLF navigational and time service transmitters.

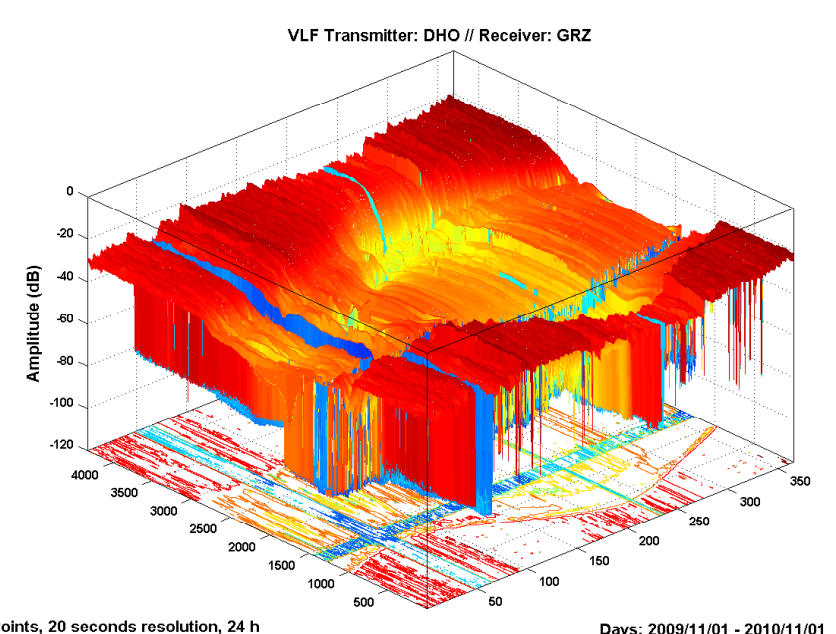

Fig. 2. VLF Amplitude data for one year - from 2009/11/01 to 2010/11/01 - between transmitter Rhauderfehn (DHO), Germany and receiver Graz (GRZ), Austria. Visible are (i) the two regular daily dips/cusps during sunrise/sunset, (ii) the noise floor during transmitter switch off, and (iii) an annual amplitude variation, especially during nighttime, with higher amplitude values in winter that decrease in summer.

\subsection{Transmitters}

Table 2 gives an overview of the transmitters and used frequencies. Detailed information on characteristics of the transmitters is proprietary to their operators and not publicly available, but variations in transmitting power or switch off during maintenance periods can be observed occasionally.

\subsection{Earth - ionosphere cavity}

For terrestrial VLF wave propagation, the cavity formed by (i) the Earth surface, both over land and sea, and in particular (ii) the lower ionosphere (Friedrich and Rapp, 2009), is crucial for variations in amplitude and phase signals at receiver end. Beside the experimental investigations, careful numerical modelling of propagation paths (Besser et al., 2010) and comparison with long term measurements are important. Figure 2 shows VLF amplitude measurements for one year continuous operation on the path DHO-GRZ.

\section{Graz VLF receiving system}

The Graz VLF system at Victor Franz HessForschungszentrum, Space Research Institute (IWF), Austrian Academy of Sciences (ÖAW), is able to receive eleven (from technically up to 12) selected transmitters located in Europe and the USA, from which eight are common within the collaboration network (Table 2). The VLF receiving chain is equipped with a wind load, thermal, and lightning protected $4 \mathrm{~m}$ antenna installed on the roof 
Table 1. Core network VLF/LF receiving stations by type (UltraMSK, 2010) and (Elettronika, 2010) and their spatial distribution. The International Network for Frontier Research on Earthquake Precursors (INFREP, 2010) in Bari, Italy, is a central node for data access.

\begin{tabular}{|c|c|c|c|c|}
\hline No.: & Akronym & Frequency Band & Receiver Location & System, Annotation, Coordinates \\
\hline 1 & GRZ & VLF & Graz, Austria & UltraMSK, N $47^{\circ} 02^{\prime} 40^{\prime \prime}$, E $15^{\circ} 28^{\prime} 48^{\prime \prime}$ \\
\hline 2 & MOS & VLF & Moscow, Russia & UltraMSK, links to Far East stations \\
\hline 3 & ITBa & VLF & Bari, Italy & OmniPal, subset of transmitters, Table 2 \\
\hline 4 & DST & VLF & Darmstadt, Germany & UltraMSK, facility in commissioning \\
\hline 5 & ITAn & VLF/LF & central Italy & Elettronika, $\mathrm{N} 42^{\circ} 25^{\prime}, \mathrm{E} 13^{\circ} 05^{\prime}$ \\
\hline 6 & ITTc & $\mathrm{VLF} / \mathrm{LF}$ & southern Italy & Elettronika, N $40^{\circ} 49^{\prime}$, E $17^{\circ} 28^{\prime}$ \\
\hline 7 & GRE & VLF/LF & Greece & Elettronika, $\mathrm{N} 40^{\circ} 34^{\prime}, \mathrm{E} 23^{\circ} 00^{\prime}$ \\
\hline 8 & TUR & VLF/LF & Turkey & Elettronika, $\mathrm{N} 40^{\circ} 23^{\prime}$, E $37^{\circ} 20^{\prime}$ \\
\hline 9 & ROM & VLF/LF & Romania & Elettronika, $\mathrm{N} 44^{\circ} 04^{\prime}$, E $28^{\circ} 38^{\prime}$ \\
\hline 10 & POR & VLF/LF & Portugal, near Evora & Elettronika, $\mathrm{N} 38^{\circ} 20^{\prime}$, W $07^{\circ} 32^{\prime}$ \\
\hline
\end{tabular}

Table 2. VLF transmitters received at station Graz, two of them are above the strict definition of the VLF frequency range from 3-30 kHz.

\begin{tabular}{|c|c|c|c|c|}
\hline No.: & Akronym & $\begin{array}{l}\text { Frequency } \\
\quad(\mathrm{kHz})\end{array}$ & Transmitter & $\begin{array}{l}\text { Geographic Coordinates: } \\
\text { Latitude, Longitude }\end{array}$ \\
\hline 1 & $\mathrm{JXN}^{* *}$ & 16.40 & Aldra, Norway & $\mathrm{N} 66^{\circ} 24^{\prime} 56^{\prime \prime}$, E $13^{\circ} 03^{\prime} 45^{\prime \prime}$ \\
\hline 2 & GBS * & 19.58 & Anthorn, UK & $\mathrm{N} 54^{\circ} 54^{\prime} 42^{\prime \prime}, \mathrm{W} 3^{\circ} 16^{\prime} 42^{\prime \prime}$ \\
\hline 3 & $\mathrm{ICV}^{*}$ & 20.27 & Tavolara, Sardinia, Italy & $\mathrm{N} 40^{\circ} 54^{\prime} 51^{\prime \prime}$, E $9^{\circ} 43^{\prime} 30^{\prime \prime}$ \\
\hline \multirow[t]{2}{*}{4} & HWU ** & 20.90 & Le Blanc, France & $\mathrm{N} 46^{\circ} 42^{\prime} 49^{\prime \prime}, \mathrm{E} 1^{\circ} 14^{\prime} 48^{\prime \prime}$ \\
\hline & & & St. Assise, France & $\mathrm{N} 48^{\circ} 32^{\prime} 48^{\prime \prime}$, E $2^{\circ} 34^{\prime} 27^{\prime \prime}$ \\
\hline 5 & NPM & 21.40 & Lualualei, Hawaii, USA & $\mathrm{N} 21^{\circ} 25^{\prime} 09^{\prime \prime}, \mathrm{W} 158^{\circ} 08^{\prime} 52^{\prime \prime}$ \\
\hline 6 & $\mathrm{GBZ}^{* *}$ & 22.10 & Skelton, UK & N $54^{\circ} 43^{\prime} 54^{\prime \prime}$, W $2^{\circ} 52^{\prime} 59^{\prime \prime}$ \\
\hline 7 & $\mathrm{DHO} *$ & 23.40 & Rhauderfehn, Germany & $\mathrm{N} 53^{\circ} 05^{\prime} 07^{\prime \prime}, \mathrm{E} 7^{\circ} 36^{\prime} 50^{\prime \prime}$ \\
\hline 8 & NAA & 24.00 & Cutler, Maine, USA & $\mathrm{N} 44^{\circ} 39^{\prime} 10^{\prime \prime}, \mathrm{W} 67^{\circ} 17^{\prime} 07^{\prime \prime}$ \\
\hline 9 & TBB & 26.70 & Bafa, Turkey & $\mathrm{N} 37^{\circ} 24^{\prime} 46^{\prime \prime}$, E $27^{\circ} 19^{\prime} 27^{\prime \prime}$ \\
\hline 10 & NRK * & 37.50 & Keflavik, Iceland & $\mathrm{N} 64^{\circ} 01^{\prime} 06^{\prime \prime}, \mathrm{W} 22^{\circ} 34^{\prime} 06^{\prime \prime}$ \\
\hline 11 & ITS * & 45.90 & Niscemi, Sicily, Italy & $\mathrm{N} 37^{\circ} 07^{\prime} 32^{\prime \prime}$, E $14^{\circ} 26^{\prime} 11^{\prime \prime}$ \\
\hline
\end{tabular}

Transmitters indicated with * were part of the predecessor OmniPal system, in operation from November 2008 to September 2009 ,

** are received, but are not part of the network.

of the building and a low noise amplifier mounted in its immediate vicinity. The VLF signal and the GPS signal (from which a pulse per second is finally derived) are routed with shielded cables into the A/C room. The signals are digitised with a MAudio Delta 44 sound-card and a special purpose software (UltraMSK) delivers the raw format of the data. The experience with the predecessor system shows that a stable thermal environment is important for data quality and to avoid drifts of the electronics. From the VLF server hardware running under Linux operating system (Fedora) behind the IWF firewall the daily data files from each transmitter are post-processed, validated, and together with quick-look plots are transferred to a file server in front of the firewall, where they are available for the team members (Fig. 3). As an example, typical daily amplitude and phase properties are shown in Fig. 4 for 23 January 2010.

\subsection{Operational modes}

The GRZ receiving station operates continuously throughout the year with a network-wide selected temporal resolution of $20 \mathrm{~s}$ for the 11 transmitters, synchronised with a GPS puls per second (PPS) electronics. In general the system could run up to a maximum sampling rate of $f_{\mathrm{s}}=96 \mathrm{kHz}$. The current facility has high reliability and availability, omitting some difficulties experienced with the previous OmniPal receiver, and routine maintenance is sufficient. 


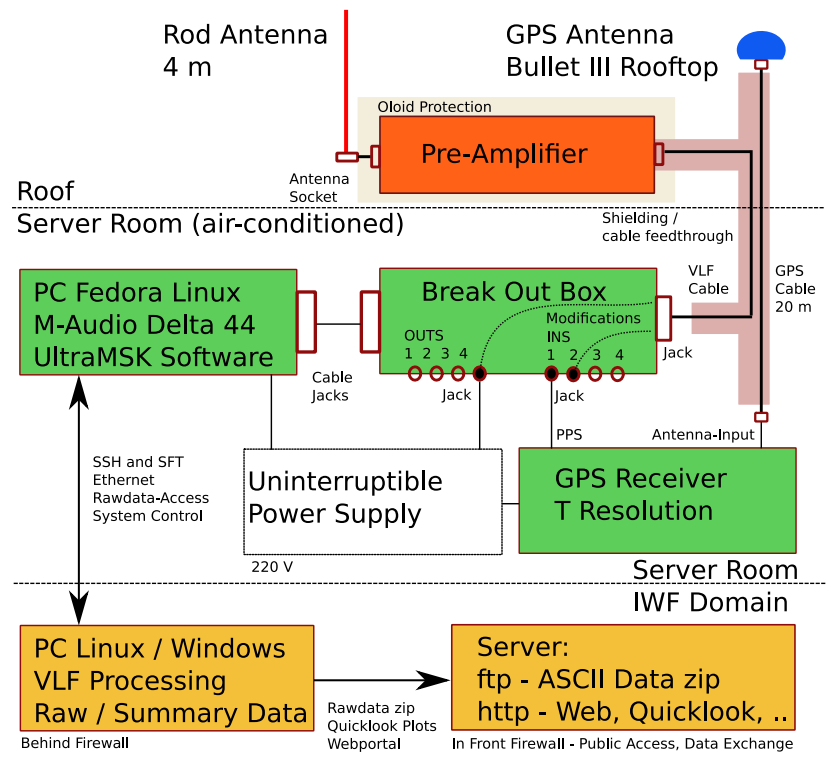

Fig. 3. Schematic diagram and dataflow of the Graz VLF facility. The equipment at the roof, exposed to atmospheric precipitation but best possible protected, gets power from the server room and delivers the VLF- and GPS-signals to the audio card of the computer. The digitised measurements are processed and finally available in 20 s resolution.

\subsection{Environmental influences}

The VLF equipment at the roof, beside the antennas, i.e. preamplifier and harness, which is exposed to the natural environment at receiving station, is passively protected with an oloid envelope and the cables are shielded. Direct solar irradiance is avoided, and rain/drizzle together with wind- or snow-load is minimised.

\subsubsection{Meteorological influences}

Experience shows that local rain affects the received VLF signals and the amplitudes/phases of each path are irregularly disturbed. Daily or seasonal temperature variations have minor influence on the nominal behaviour of the facility. In order to quantify the local environment during the four seasons, meteorological parameters like (i) temperature, (ii) pressure and (iii) humidity are continuously recorded with a professional weather station located at Lustbühel $\sim 3 \mathrm{~km}$ air-line distance away, Fig. 5.

\subsubsection{Geomagnetic activity}

In order to discriminate between the various influencing sources, local and global geomagnetic activity indices are considered. As global magnetic activity/disturbance proxies serves the $\mathrm{Kp}$ and Dst indices, local geomagnetic variations are considered through ULF measurements from Nagycenk observatory, Hungary, which is part of the ULF SEGMA chain.

\subsubsection{Artefacts}

Located in urban area, the facility is in principle exposed to higher man-made electromagnetic noise levels. Some small and intermittent disturbances in the VLF data time series (amplitude and phase variations) are registered without conclusiveness about the source.

\section{Scientific results}

We divide the investigations in two categories: (i) statistical parameters of the VLF amplitude and phase time series, and (ii) individual event studies with specific seismoelectromagnetic data analysis methods (albeit statistics is involved here too).

\subsection{Statistical data}

One year of VLF amplitude measurements are shown in Fig. 6. At first glance one can observe typical patterns at sunrise and sunset for the various paths, details are showing up after correlation of the signals.

\subsection{Event based studies}

As requirement for a possible (seismo-electromagnetic) event at least one VLF path must be influenced and several control paths should show nominal behaviour. The common methods are based on (i) night time amplitudes, usually four hours around midnight, and (ii) terminator time (TT) variations in amplitude and/or phase. The topology of the VLF receiver network with geographically distributed stations further pinpoint the source location and the size and uncertainty of this area/node could be estimated.

\section{Conclusions and outlook}

Since 2009 the Graz VLF facility is an operational and integral part of the European VLF network. Considering the pros and cons, the upgrade from the successful OmniPal to the UltraMSK system further increased resolution and robustness. The $20 \mathrm{~s}$ temporal resolution is adequate for seismoelectromagnetic investigations, but higher sampling rates are preferable for fast and transient VLF phenomena, e.g. in astrophysical investigations. Environmental monitoring is a major issue to discriminate electromagnetic signals in VLF band related with EQs from other geophysical influences and artefacts. 

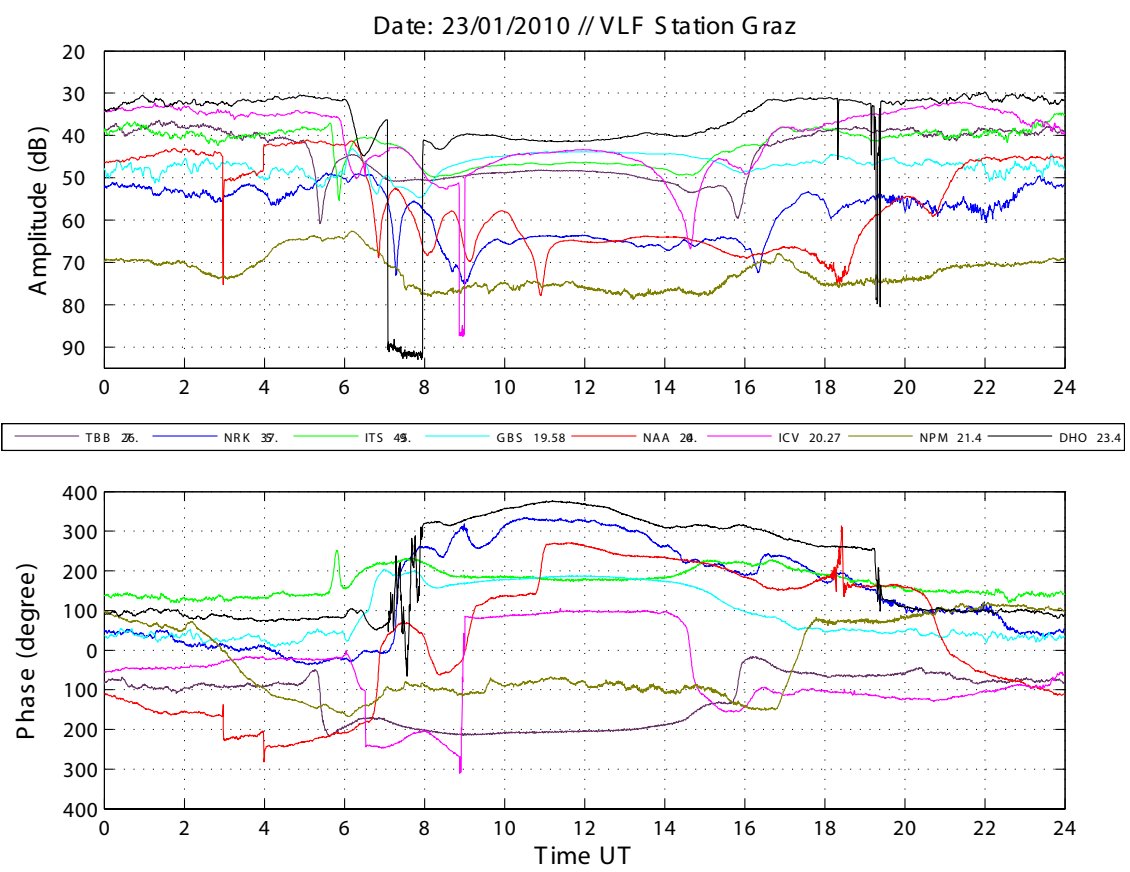

Fig. 4. Typical quiet daily VLF amplitude and phase profiles for the 8 transmitters at GRZ receiving station, shown for 23 January 2010. Amplitude variations at terminators are accompanied by phase changes. In the period 07:00-08:00 UT the transmitter DHO (black trace) is switched off and has some spikes in the evening, ICV has an interruption for a few minutes around 09:00 UT, NAA reduces $\sim 6 \mathrm{~dB}$ power between 03:00-04:00 UT.
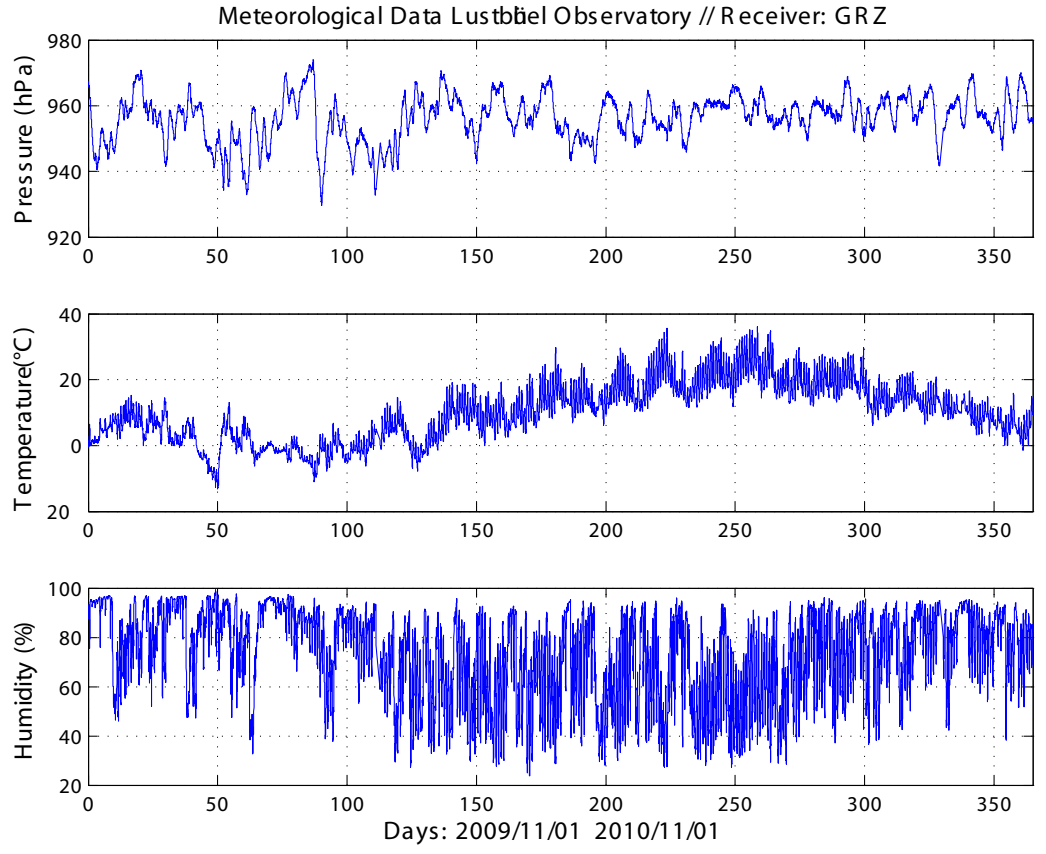

Fig. 5. Meteorological data for one year from a professional weather station located at Lustbühel observatory a few km air-line distance from GRZ receiving station away. This facility delivers continuously (i) atmospheric pressure, (ii) temperature, and (iii) relative humidity data at a selectable $1 \mathrm{~min}$ or $10 \mathrm{~min}$ temporal resolution. 

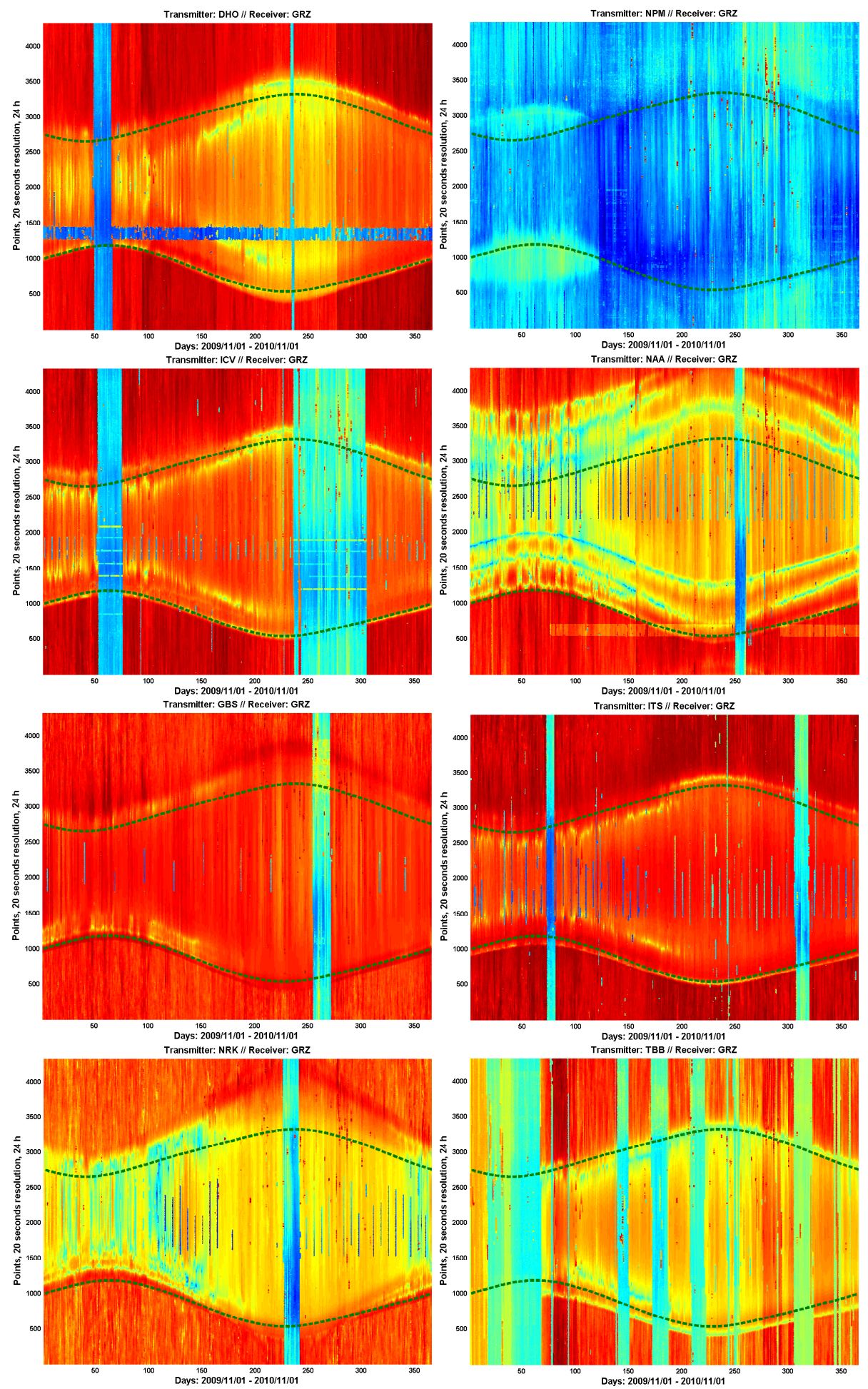

Fig. 6. Colour coded VLF amplitudes - from 2009/11/01 to 2010/11/01 - for the paths from the 8 transmitters of the network listed in Table 2 to GRZ receiving station; upper left is the top view from Fig. 2. From top left to bottom right the paths are $\{$ DHO, NPM, ICV, NAA, GBS, ITS, NRK, TBB\}-GRZ. Superposed are the official sunrise and sunset times for GRZ (dotted lines); civil-, nautical-, and astronomical times are not shown. 
Acknowledgements. Martin Volwerk wrote software for VLF calculations, Georg Kirchner and his team at Lustbühel observatory provided meteorological data, Gerald Kögler made adaptions at the building for the VLF facility, and Herbert I. Lichtenegger and Magda Delva gave impetus to theoretical considerations. The Graz VLF facility is funded by IWF/ÖAW and available through the webportal http://www.sem.iwf.oeaw.ac.at.

Edited by: T. Maggipinto

Reviewed by: I.-A. Moldovan and another anonymous referee

\section{References}

Besser, B. P., Eichelberger, H. U., and Schwingenschuh, K.: Modelling of VLF ionospheric propagation related to earthquake events, 8th International Conference Problems of Geocosmos, 2010.

Biagi, P. F., Castellana, L., Maggipinto, T., Loiacono, D., Schiavulli, L., Ligonzo, T., Fiore, M., Suciu, E., and Ermini, A.: A pre seismic radio anomaly revealed in the area where the Abruzzo earthquake $(M=6.3)$ occurred on 6 April 2009, Nat. Hazards Earth Syst. Sci., 9, 1551-1556, doi:10.5194/nhess-91551-2009, 2009.

Biagi, P. F., Castellana, L., Maggipinto, T., Loiacono, D., Schiavulli, L., Ligonzo, T., Fiore, M., Suciu, E., and Ermini, A.: Brief communication "A pre seismic radio anomaly revealed in the area where the Abruzzo earthquake $(M=6.3)$ occurred on 6 April 2009", Nat. Hazards Earth Syst. Sci., 10, 215-216, doi:10.5194/nhess-10-215-2010, 2010.

Boudjada, M. Y., Schwingenschuh, K., Döller, R., Rohznoi, A., Parrot, M., Biagi, P. F., Galopeau, P. H. M., Solovieva, M., Molchanov, O., Biernat, H. K., Stangl, G., Lammer, H., Moldovan, I., Voller, W., and Ampferer, M.: Decrease of VLF transmitter signal and Chorus-whistler waves before l'Aquila earthquake occurrence, Nat. Hazards Earth Syst. Sci., 10, 14871494, doi:10.5194/nhess-10-1487-2010, 2010.

Elettronika company website: http://www.elettronika.it/, last access: April 2011, 2010.

Friedrich, M. and Rapp, M.: News from the Lower Ionosphere: A Review of Recent Developments, Surv. Geophys., 30, 525-559, doi:10.1007/s10712-009-9074-2, 2009.

Hayakawa, M.: VLF/LF Radio Sounding of Ionospheric Perturbations Associated with Earthquakes, Sensors, 7, 1141-1158, doi:10.3390/s7071141, 2007.

Hayakawa, M.: Lower ionospheric pertubations associated with earthquakes, as detected by subionospheric VLF/LF radio waves, in: Electromagnetic Phenomena Associated with Earthquakes, Transworld Research Network, Trivandrum, India, 2009.

Hayakawa, M. and Hobara, Y.: Current status of seismoelectromagnetics for short-term earthquake prediction, Geomatics, Natural Hazards and Risk, 1(2), 115-155, doi:10.1080/19475705.2010.486933, 2010.

INFREP: http://beta.fisica.uniba.it/infrep/, last access: April 2011, 2010.

Molchanov, O. A. and Hayakawa, M.: Seismo Electromagnetics and Related Phenomena: History and latest results, Terrapub, Tokyo, Japan, 2008.
Němec, F., Santolík, O., and Parrot, M.: Decrease of intensity of ELF/VLF waves observed in the upper ionosphere close to earthquakes: A statistical study, J. Geophys. Res. (Space Physics), 114, A04303, doi:10.1029/2008JA013972, 2009.

Prattes, G., Schwingenschuh, K., Eichelberger, H. U., Magnes, W., Boudjada, M., Stachel, M., Vellante, M., Wesztergom, V., and Nenovski, P.: Multi-point ground-based ULF magnetic field observations in Europe during seismic active periods in 2004 and 2005, Nat. Hazards Earth Syst. Sci., 8, 501-507, doi:10.5194/nhess-8-501-2008, 2008.

Prattes, G., Schwingenschuh, K., Eichelberger, H., Besser, B., Magnes, W., Stachel, M., Vellante, M., Villante, U., Nenovski, P., and the SEGMA Team: Seismo-magnetic multi-point ULF studies before the 2009 L'Aquila earthquake using the South European GeoMagnetic Array, Geophys. Res. Abstracts, 12, EGU2010-9269-1, 2010a.

Prattes, G., Schwingenschuh, K., Eichelberger, H., Stachel, M., Magnes, W., Vellante, M., Villante, U., Nenovski, P., and Wesztergom, V.: Signal Processing of Ultra Low Frequency (ULF) magnetic field data related to seismic activity in Europe during 2008 and 2009, in: ISRSSP'10, 2nd International Symposium on Radio Systems and Space Plasma, 109-112, $2010 \mathrm{~b}$.

Pulinets, S. and Boyarchuk, K.: Ionospheric Precursors of Earthquakes, Springer Berlin Heidelberg New York, Germany, 1 Edn., 2004.

Rozhnoi, A., Solovieva, M., Molchanov, O., Schwingenschuh, K., Boudjada, M., Biagi, P. F., Maggipinto, T., Castellana, L., Ermini, A., and Hayakawa, M.: Anomalies in VLF radio signals prior the Abruzzo earthquake $(M=6.3)$ on 6 April 2009, Nat. Hazards Earth Syst. Sci., 9, 1727-1732, doi:10.5194/nhess-91727-2009, 2009.

Schwingenschuh, K., Villante, U., Vellante, M., De Lauretis, M., Francia, P., Piancatelli, A., Pietropaolo, E., Meloni, A., Palangio, P., Prattes, G., Boudjada, M., Magnes, W., Eichelberger, H., Zhang, T. L., Nenovski, P., and Rozhnoi, A.: The April 6, 2009 Earthquake at L'Aquila: A preliminary seismo-magnetic analysis of multipoint ground-based magnetic field measurements., AGU fall meeting, Nat. Hazards (NH), ID:717 182, 2009.

Schwingenschuh, K., Eichelberger, H., Prattes, G., Besser, B. P., Simoes, F., Rozhnoi, A., Solovieva, M., Molchanov, O., Friedrich, M., Stangl, G., Boudjada, M. Y., Biernat, H., Döller, R., Biagi, P. F., and Nenovski, P.: Sub-ionospheric and transionospheric VLF wave propagations and its relation to seismoelectromagnetic phenomena, in: ISRSSP'10, 2nd International Symposium on Radio Systems and Space Plasma, 113-116, 2010a.

Schwingenschuh, K., Simoes, F., Rozhnoi, A., Friedrich, M., Stangl, G., Boudjada, M. Y., Besser, B. P., Eichelberger, H., Prattes, G., and Biagi, P. F.: Seismo-electromagnetic variations in the VLF/LF sub-ionospheric waveguide before, during and after the April 6, 2009 earthquake at L'Aquila, Geophys. Res. Abstracts, 12, EGU2010-9173, 2010b.

UltraMSK company website, http://ultramsk.com/, last access: April 2011, 2010. 